\title{
announcements/call for papers
}

\section{2nd Conference on Hurricanes and Tropical Meteorology, 19-23 May 1997, Fort Collins, Colorado}

The 22nd Conference on Hurricanes and Tropical Meteorology, sponsored by the American Meteorological Society and organized by the AMS Committee on Tropical Meteorology and Tropical Cyclones, will be held 19-23 May 1997 at the University Park Holiday Inn, Ft. Collins, Colorado.

Papers in all areas of tropical meteorology were invited. In addition, special sessions are planned on the extraordinarily active 1995 hurricane season, TOGA COARE, and MCTEX.

The deadline for abstracts has passed. A preprint volume will be included with registration and available for purchase after the meeting. The program for this conference was published in the February 1997 and the general information was published in the March 1997 issues of the Bulletin.

The best student paper presented will receive the Max Eaton Award, consisting of a certificate and monetary award. At the conference, the AMS Tropical Committee will also present the Banner Miller Award, recognizing the best paper on tropical cyclones or tropical meteorology published during the preceding four years.

For information contact Cochairpersons Wayne Schubert, Dept. of Atmos. Sci., Colorado State Univ., Ft. Collins, CO 80523 (tel: 970-491-8521; fax: 970-4918449; e-mail: waynes@ hadley.atmos.colostate.edu)or Richard Johnson, Department of Atmospheric Science, Colorado State University, Ft. Collins, CO 80523 (tel: 970-491-8321; e-mail: rhj@vortex.atmos.colostate.edu) or on web site (http://tornado.atmos.colostate.edu/ hurrconf). (2/96; r4/96; r5/96; r6/96; r11/96; r2/97; r3/97)

\section{AGU Spring Meeting, 27-30 May 1997, Baltimore, Maryland}

The American Geophysical Union (AGU) Spring Meeting will be held in Baltimore, Maryland, 27-30 May 1997.

For additional information pleasecontact the AGU Meetings Department, 2000 Florida Avenue, North West, Washington, DC 20009 (tel: 202-462-6900; fax: 202-328-0566; e-mail: meetinginfo@kosmos.agu.org). $(3 / 97)$

\section{2nd NATO/CCMS International Technical Meeting on Air Pollution Modeling and Its Application, 2- 6 June 1997, Clermont-Ferrand, France}

The 22nd NATO/CCMS International Technical Meeting on Air Pollution Modelling and Its Application (ITM) will be held 2-6 June 1997 in Clermont-Ferrand, France. The American Meteorological Society is a cooperating organization.

The deadline for abstracts has passed. Details of this meeting were published in the July-August 1996 issues of the Bulletin.

For information contact Sven-Erik Gryning, Dept. of Meteorology and Wind Energy, Risoe National Lab., 4000 Roskilde, Denmark (e-mail: gryning@risoe.dk) or Nadine Chaumerliac, LaMP, Universite Blaise PascalCNRS, 24 Avenue des Landain, F-63177 Aubiere, France (e-mail: chaumerl@opgc.univ-bpclermont.fr). (7/96; r9ł96; r12/96; r1/97)

31 st Annual Congress of the Canadian Meteorological and Oceanographic Society, 2-6 June 1997, Saskatoon, Saskatchewan, Canada

The 31st Annual Congress of the Canadian Meteorological and Oceanographic Society will be held at the University of Saskatchewan, Saskatoon, SK, Canada, 26 June 1997. The American Meteorological Society is a cooperating organization.

Details of this congress were published in the November 1996 issue of the Bulletin. Most queries regarding Congress '97 may be answered by accessing: http:// ecsask65.innovplace.saskatoon.sk.ca/pages/cmos97/ congrs97.html.

For scientific program or commercial exhibits information contact G. S. Strong (tel: 306-975-5809; fax: 306975-6516; e-mail: strong@nhrisv.nhrc.sk.doe.ca). For registration, accommodation, or other local arrangements contact Joe Eley (tel: 306-975-5685; fax: 306-975-6516; e-mail: EleyJ@nhrisv.nhrc.sk.doe.ca). (11/96; r1/97)

\section{AMS Workshop on COMET Interactive Weather Education for the 21 st Century, 17 June 1997, Snowbird, Utah}

The AMS Workshop on COMET Interactive Weather Education for the 21st Century, organized by the AMS Board of Broadcast Meteorology and sponsored by the American Meteorological Society, will be held on 
17 June 1997, in Snowbird, Utah prior to the 26th Conference on Broadcast Meteorology.

COMET (Cooperative Program for Operational Meteorology, Education and Training) is the interactive educational program that has caused a great deal of interest and many favorable comments within the broadcast community. The workshop will provide an opportunity for participants to receive hands-on experience operating some of the COMET modules while absorbing their content, with an eye toward obtaining COMET modules for individual use at participants' home and/or office locations. The COMET Program: Opportunities for Acquiring Mesoscale Meteorological Expertise.

During the 1980s, the National Weather Service (NWS) embarked on a major modernization program. As a key part of this effort, NWS management emphasized strengthening the professional preparation and current qualifications of operational meteorologists to apply mesoscale data effectively. A second goal was to accelerate the incorporation of research findings into operational practices. At the request of the NWS, the UCAR Board of Trustees established COMET in 1989. The COMET Program was originally envisioned as a broad effort to affect meteorology education and training in the United States. However, the program has recently been involved in activities to enhance meteorology education in universities and meteorological services throughout the world.

The COMET Program's mission is to serve as a premier resource that supports, enhances, and stimulates the communication and application of scientific knowledge of the atmospheric and related sciences for the operational and educational communities. Four COMET subprograms have been instituted to meet these objectives, Classroom Based Education and Training (CBET), Multimedia Based Education and Training (MBET), Outreach, and COMET Educational Resource Center (CERC). Timothy Spangler (Director) and Ron Alberty (Deputy Director) direct the COMET Program. Greg Byrd leads CBET, Joe Lamos leads MBET, Vickie Johnson leads Outreach, and Brian Heckman leads CERC.

This workshop will: 1) present a brief overview of how each of the above groups contribute to the overall COMET mission, 2) will include demonstrations of some learning techniques developed by COMET staff; and 3) will offer hands-on learning opportunities.

The program for this workshop was published in the March 1997 issue of the Bulletin. For further information contact: Mike Graham, WAFB Television, 844 Government St., Baton Rouge, LA 70802 (tel: 504-383-9999; fax: 504-379-7880; e-mail: wkk5d1@ix.netcom.com) or Dave Miller, WFRV Television, 1181 East Mason, Green Bay, WI 54301 (tel: 414-437-5411; fax: 414-4374576; e-mail: davegb@dct.com). (12/96; r1/97)

\section{6th Conference on Broadcast Meteorology, 18-21 June 1997, Snowbird, Utah}

The 26th Conference on Broadcast Meteorology, organized by the AMS Board of Broadcast Meteorology and sponsored by the American Meteorological Society, will be held 18-21 June 1997 in Snowbird, Utah. The conference will be preceded by a workshop on 17 June.

An exhibit program is also being planned, but space is limited. If you are interested in exhibiting please contact Monica Tolson (tel: 202-682-9006, e-mail: tolson@dc.ametsoc.org) to reserve a space and obtain a contract.

Deadline for abstracts has passed. Papers were solicited in the following areas: 1) Education-How are you and your station educating your audience? What kind of products do you use on air? 2) Special Weather Events and the Weather Center-Has there been an event of special and/or severe weather in your area this year? 3) International Weathercasting - One of the most well-received sessions of the 1996 conference was about how television stations and networks in other countries cover both routine and special weather events. 4) The Future-How are you incorporating new technology and ideas into your weathercasts, into your weather center, and into your school and outside presentations? and 5) Computers and the Internet-What is the latest on the Internet and the world wide web? The program for this conference was published in the March 1997 issue of the Bulletin.

For further information on the program contact: Mike Graham, WAFB Television, 844 Government St., Baton Rouge, LA 70802 (tel: 504-383-9999; fax: 504-3797880; e-mail: wkk5dl@ix.netcom.com) or Dave Miller, WFRV Television, 1181 East Mason, Green Bay, WI 54301 (tel: 414-437-5411; fax: 414-437-4576; e-mail: davegb@dct.com). (8/96; r9/96; r12/96; r1/97)

\section{$11^{\text {th }}$ Conference on Atmospheric and Oceanic Fluid Dynamics, Tacoma, Washington, 23-27 June, 1997}

The 11th Conference on Atmospheric and Oceanic Fluid Dynamics, sponsored by the American Meteorological Society and organized by the AMS Committee on Atmospheric and Oceanic Waves and Stability, will be held 23-27 June 1997 in Tacoma, Washington, jointly with the 10th Conference on the Middle Atmosphere.

The deadline for abstracts has passed. Papers were solicited in all areas of atmospheric and oceanic fluid dynamics, including linear and nonlinear wave propagation, instability, turbulence, and convection. The program for this conference was published in the March 1997 issue of the Bulletin. A preprint volume will be included with registration and available for purchase after the meeting. 
For further information contact the Conference Chairperson, Christopher Bretherton, University of Washington, Atmospheric Sciences, Box 351640, Seattle, WA 98195 (tel: 206-685-7414, fax: 604-6859302; e-mail: breth@amath.washington.edu ). (9/96; $\mathrm{r} 10 / 96 ; \mathrm{r} 1 / 97 ; \mathrm{r} 3 / 97)$

10th Conference on the Middle Atmosphere, 2327 June 1997, Tacoma, Washington

The 10th Conference on the Middle Atmosphere, sponsored by the American Meteorological Society and organized by the AMS Committee on Middle Atmosphere, will be held 23-27 June in Tacoma, Washington. This conference will be collocated with the 11th Conference on Atmospheric and Oceanic Fluid Dynamics.

The deadline for abstracts has passed. Papers were solicited in all areas of middle atmosphere science, including dynamics, trace constituent transport and chemistry, and radiation. The program for this conference was published in the March 1997 issue of the Bulletin.

We seek a balanced program of observational studies (analyses of satellite and in situ aircraft data) and modeling work (highly-idealized to full general circulation model simulations). Specific scientific topics which will be emphasized include 1) trace constituent transport, in particular tropical-midlatitude interactions, 2) stratospheric chemistry, 3) aerosol effects, 4) chemical and dynamical coupling of the troposphere and middle atmosphere, 5) long-term ozone variability and global climate effects, 6) the quasi-biennial oscillation, 7) mesospheric dynamics, and 8) data assimilation. Joint sessions with the 11th Conference on Atmospheric and Oceanic Fluid Dynamics may include 1) polar vortex dynamics and 2) effects of gravity waves.

For further information contact the Conference Chairperson: William Randel, NCAR, P.O. Box 3000, Boulder, CO 80307 (tel: 303-497-1439; fax: 303-4971492; e-mail: randel@ucar.edu). (9/96; r11/96; r1/97)

\section{WMO Workshop on Measurement of Cloud Properties for Forecasts of Weather, Air Quality, and Climate, 23-27 June 1997, Mexico City, Mexico}

A Workshop on Measurement of Cloud Properties for Forecasts of Weather, Air Quality, and Climate, sponsored by the World Meteorological Organization (WMO) and hosted by the National University of Mexico, will be conducted 23-27 June 1997 in Mexico City, Mexico. The American Meteorological Society is a cooperating organization.

Details of this workshop were published in the September-November 1996 issues of the Bulletin. For more information contact Graciela Raga, Centro de Ciencias de la Atmosfera, UNAM, Ciudad Universitaria, 04510 Mexico DF, Mexico (tel: 525-622-4086; fax: 525-616-
0789; e-mail: conf97@nefelos.atmosfcu.unam.mx) or Darrel Baumgardner, NCAR, P.O. Box 3000, Boulder, CO 80303 (tel: 303-497-1054; fax: 303-497-1092; email: darrel@ncar.ucar.edu). (9/96; r10/96; r1/97)

\section{IAMAS \& IAPSO Conference, 1-9 July 1997, Melbourne, Victoria, Australia}

The 1997 Joint Assemblies of the International Association of Meteorology and Atmospheric Sciences and the International Association for Physical Sciences of the Ocean will be holding a conference 1-9 July 1997 at the World Congress Centre in Melbourne, Victoria, Australia. The conference is sponsored by the Australian Academy of Science, CSIRO Division of Atmospheric Research, and CSIRO Division of Oceanography Bureau of Meteorology. The American Meteorological Society is a cooperating organization.

The deadline for abstracts has passed. For further information contact IAMAS/IAPSO Secretariat, Convention Network, 224 Rouse Street, Port Melbourne, Victoria 3207, Australia (tel: 61-3-9646-4122; fax: 613-9646-7737; e-mail: convnet@peg.apc.org). (1/97; $\mathrm{r} 2 / 97 ; \mathrm{r} 4 / 97)$

\section{2 th Symposium on Boundary Layers and Turbulence, 28 July-1 August 1997, Vancouver, British Columbia, Canada}

The 12th Symposium on Boundary Layers and Turbulence, sponsored by the American Meteorological Society and organized by the AMS Committee on Boundary Layer and Turbulence, will be held 28 July1 August 1997 at the University of British Columbia (UBC), Vancouver, British Columbia, Canada. The Canadian Meteorological and Oceanographic Society is a cosponsor.

Session topics will include surface layers, convective PBLs, stable PBLs, oceanic boundary layers, surface-flux parameterization, moisture budget, effects of surface heterogeneities, aggregation and area averaging, biosphere models, turbulence in vegetative canopies, complex terrain and mountain boundary layers, microstructure in oceans and atmospheres, coherent structures, nonlocal closures, mixing and internal waves, dynamics of stratified turbulence, boundarylayer clouds, entrainment processes, atmospheric PBL modeling, simulations including LES and DNS, and analysis techniques including wavelets, fractals, and chaos. Some sessions will be devoted to field programs, such as GCIP results, TOGA-COARE BL results, LIFT results, COAST 96, other new field program results, and a commemorative session for the 30th anniversary of the Kansas surface-layer experiment.

The deadline for abstracts has passed. A preprint volume will be included with registration and available for purchase after the meeting. The program for this 
symposium is published in the April 1997 issue of the Bulletin.

A limited number, but wide variety, of accommodations are available on campus. Additional accommodations are available in downtown hotels, but these are more expensive because of the high tourist season in summer, and they are about a 30-minute bus ride from campus. For accommodations on campus, we recommend you make your reservations by 26 June 1997 . Write or call the UBC Conference Centre, 5961 Student Union Blvd., Vancouver, BC V6T 2C9, Canada (tel: 604822-1010; fax: 604-822-1001; e-mail: reservation@ brock.housing.ubc.ca). Be sure to mention the American Meteorological Society Conference on Boundary Layers and Turbulence.

Events to be held include: registration starting Sunday evening, Tuesday evening Museum of Anthropology (on campus), Wednesday evening banquet in Great Hall of the First Nations (native Canadian) Long House on campus. Optional city and regional tours are tentatively being planned for other days.

For further information see world wide web site http://www.millersv.edu/ rdclark/blt.html or contact the Program Chairperson: Roland Stull, Atmospheric Science Programme, Dept. of Geography, Univ. of British Columbia, 1984 West Mall, Vancouver, BC V6T 1Z2, Canada (tel: 604-822-5901; fax: 604-822-6150; email: rstull@geog.ubc.ca). (r8/96; r9/96; r11/96; r2t97; r4/97)

\section{Call for Papers}

Workshop on Biogenic Hydrocarbons in the Atmospheric Boundary Layer, 24-27 August 1997, Charlottesville, Virginia

A Workshop on Biogenic Hydrocarbons in the Atmospheric Boundary Layer will be held at the University of Virginia, Charlottesville, Virginia, 24-27 August 1997. The workshop is sponsored by the American Meteorological Society (AMS), cosponsored by Environment Canada, and organized by the AMS Committee on Atmospheric Chemistry. Other potential cosponsors include the Environmental Protection Agency (EPA) and the National Science Foundation (NSF).

Biogenic volatile organic compounds (BVOCs) introduced in the lower troposphere can significantly influence tropospheric chemistry thereby impacting the abundance of ozone and other oxidants. This has prompted a great interest in determining the origin of these hydrocarbons, quantifying their rate of emissions and identifying their fate in the atmosphere. Considerable progress has been made in all these aspects and it now appears timely to take stock of recent developments to review what has been learned and discuss future research endeavors.
This topical meeting is organized to address the following central themes: 1) Plant physiological and environmental controls on BVOC emissions; 2) Measurements and modeling of BVOC emissions at the foliage and ecosystem levels. Work related to gas exchange using cuvette systems and micrometeorological techniques will be considered; 3) Atmospheric observations. Results from recent measurement campaigns, and new developments of analytical methods and measurement technologies will be included; and 4) Chemical mechanisms for $B V O C$. Laboratory kinetic studies and smog chamber experiments will be reviewed; 5) Photochemically modeling the role of BVOCs. This will include the application of chemical mechanisms, combined with emission model developments, to examine regional and global chemical processes.

Conference presentations will come primarily from invited speakers, but unsolicited contributions are welcome provided that notifications arrive before 1 June 1997. The plan calls for oral presentations during approximately 3-hour long sessions in the morning and evening, with the afternoons reserved for informal discussions. One aim of the workshop is to foster future research endeavors. Accommodation will be available at hotels within walking distance of the conference place. Accommodation fees range between $\$ 65$ and $\$ 125$.

Further information can be obtained from the following persons: Theme 1: Thomas D. Sharkey, Dept. of Botany, 430 Lincoln Dr., Univ. of Wisconsin, Madison, WI 53706 (tel: 608-262-6802; fax 608-262-7509; email: tsharkey@facstaff.wisc.edu); Theme 2\&3: Jose D. Fuentes, Dept. of Environmental Sciences, Clark Hall, Univ. of Virginia, Charlottesville, VA 22903 (tel: 804-9822654; fax: 804-982-2137; e-mail: jf6s@virginia.edu) or Alex Guenther, Atmospheric Chemistry Division, NCAR, 1850 Table Mesa Dr., Boulder, CO 80303 (tel: 303-497-1447; fax: 303-497-1477; e-mail: guenther@ucar.edu); Theme 4\&5: Jan W. Bottenheim, Atmospheric Environment Service, Environment Canada, 4905 Dufferin Street, Downsview, ON M3H 5T4, Canada, (tel: 416-739-4838; fax: 416-739-5704; email: jan.bottenheim@ec.gc.ca); All Themes (Europeans only): Rainer Steinbrecher, Inst. Atmospharische Umweltforschung Kreuzeckbahnstrabe 19, d-82467 Garmisch-Partenkirchen (tel: +49 (0) 88 21/1 83-217; fax: +49(0) 88 21/7 35 73; e-mail: Rainer_Steinbrecher_ at_IFUBox@ifu.fhg.de). (4/97)

\section{8th Conference on Radar Meteorology, 7- 12 September 1997, Austin, Texas}

The 28th Conference on Radar Meteorology sponsored by the American Meteorological Society and organized by the AMS Committee on Radar Meteorology, will be held 7-12 September 1997 at the Hyatt Regency 
Hotel, Austin, Texas. A special session on Atmospheric Electricity will be held in conjunction with this conference.

This conference will celebrate the 50th anniversary of the radar conference series. The Program Committee has planned for a special session devoted to an historical review of radar meteorology, featuring five invited speakers, covering the following themes: 1) the early days of radar meteorology, 2) revolutionary steps in radar meteorology and its applications, 3) a look ahead: a technological perspective, 4) a look ahead: a scientific perspective, and 5) a look ahead: an educational perspective.

Exhibitors will be alerted to the 50th anniversary of this conference in the event that they might wish to join in the celebration. An exhibit program is being planned, but space is limited. If you are interested in exhibiting, please contact Monica Tolson (tel: 202-682-9006, e-mail: tolson@dc.ametsoc.org) to reserve a space and obtain a contract.

Special emphasis is being placed on applications of radar data in addressing hydrological and weather forecasting concerns. Other areas that will be emphasized include: results from the VORTEX program; the technology and applications of cloud and bistatic radars; studies using profiler networks, spaceborne radar, and multiparameter polarimetric radars; radar meteorology education and training; radar studies of precipitating cloud systems; radar measurements over complex terrain; radar measurements in relation to satellite IR and passive microwave measurements; interdisciplinary studies using radar observations in modeling and simulations; and advances in signal processing and radar design. A special session on the applications of radar meteorology in the study of storm electrification is also planned.

The deadline for abstracts has passed. Papers on all aspects of radar meteorology were invited. AMS will provide instructions to authors of accepted abstracts. Complete, camera-ready manuscripts (page length to be determined at a later date) including photos and diagrams, must be submitted not later than 2 June 1997 to AMS Headquarters. Page charges and any additional charges for photo processing will be assessed to defray printing costs. A preprint volume will be included with registration and available for purchase after the meeting. Inquires may be directed to the program chairperson via e-mail: mikeb@ariel.tamu.edu.

To honor the memory of Spiros Geotis, who in his career of more than 40 years inspired many students, the Spiros G. Geotis Prize will be awarded for the best student paper. Papers will be judged on scientific content and presentation at the conference. For further information contact Michael I. Biggerstaff, program chairperson, Dept. of Meteorology, Texas A\&M University, College Station, TX 77843-3150 (tel: 409-847-9090; fax: 409-862-4466). (6/96; r11/96; r2/97; 3/97)
Special Session on Atmospheric Electricity, 712 September 1997, Austin, Texas

A Special Session on Atmospheric Electricity is planned to be held in conjunction with the 28th Conference on Radar Meteorology, 7-12 September 1997 at the Hyatt Regency Hotel, Austin, Texas. This special session is sponsored by the American Meteorological Society and the AMS Committee on Atmospheric Electricity.

Rather than hold a joint conference or a separate conference, the committee has decided instead to invite submission of relevant papers to the Conference on Radar Meteorology. A special session on the applications of radar meteorology in the study of storm electrification is planned. In addition, papers on any aspect of atmospheric electricity and storm electrification related to radar meteorology were invited and will be placed in the appropriate sessions.

The deadline for abstracts has passed. AMS will provide instructions to authors of accepted abstracts. Complete camera-ready manuscripts (page length to be determined at a later date), including photos and diagrams, must be received at AMS Headquarters by 1 June 1997. Page charges and any additional charges for photo processing will be assessed to defray printing costs. Registrants will receive a preprint volume at the conference. Please see the Call for Papers for the 28th Conference on Radar Meteorology for further details. Contact William H. Beasley, Chairperson, Committee on Atmospheric Electricity, School of Meteorology, Univ. of Oklahoma, Norman, OK 73019 (e-mail: wbeasley@ou.edu). (10/96; r11/96; r3/97)

\section{Announcement}

A\&WMA/AGU International Specialty Conference on Visual Air Quality, Aerosols, and Global Radiation Balance, 9-12 September 1997, Bartlett, New Hampshire

Visual Air Quality, Aerosols, and Global Radiation Balance, an international specialty conference sponsored by the Air \& Waste Management Association and the American Geophysical Union, will be held 912 September 1997, in Bartlett, New Hampshire, located near Mt. Washington. The American Meteorological Society is a cooperating organization.

The conference will address advances in the scientific understanding of the transfer of visible and infrared radiation through the atmosphere and of the origins, physics, and chemistry of the aerosols that scatter and absorb that radiation. The effects of air pollution on both visibility in urban and scenic areas and on climate will be addressed. Short courses related to the conference topics will be offered on 8 September.

The deadline for abstracts has passed. Peer-reviewed 
versions of conference papers will be published after the conference in special sections of the Journal of the A\&WMA and the Journal of Geophysical Research.

For further information, contact Ivar Tombach, ENSR, 1220 Avenida Acaso, Camarillo, CA 93012-8727 (fax: 805-388-3577; e-mail: visibility@ensr.com). $(4 / 97)$

Fifth International Congress of the Brazilian Geophysical Society, 28 September-2 October 1997, Sao Paulo, Brazil

The Fifth International Congress of the Brazilian Geophysical Society, 28 September-2 October 1997, Sao Paulo, Brazil. The American Meteorological Society is a cooperating organization.

The congress is intended to foster the advance and integration of the various geophysical sciences and the cooperation among universities and business enterprises, worldwide scientific organizations and individual geophysicists and to promote general educational activities.

The technical program will include oral and poster sessions on the following topics: atmospheric and space sciences, earth solid geophysics, marine geophysics, geophysics applied to oil exploration, to groundwater exploration, to mining, to engineering, environmental and geological mapping.

The deadline for extended abstracts is 30 May 1997. For more information contact on the technical program committee chairpersons: Icaro Vitorello or Antonio Padilha (tel: 55-123-25-6784 or 55-123-25-6807; fax: 55-123-25-6810; e-mail: icaro@dge.inpe.br or e-mail: padilha@das.inpe.br). (1/97)

1997 EUMETSAT Meteorological Satellite Data User's Conference, 29 September-3 October 1997, Brussels, Belgium

The 1997 EUMETSAT Meteorological Satellite Data User's Conference will be held 29 September-3 October 1997, Brussels, Belgium. The conference will take place in the Royal Museums of Art and History in the centre of Brussels and is being organized in cooperation with KMI, the National Meteorological Service of Belgium. The American Meteorological Society is a cooperating organization.

This 1997 event will address a wide range of meteorological satellite data applications. It is the aim to broaden the scope of the conference and increase interaction between different groups of users of meteorological satellite data.

Institutions or individuals requiring further information about this conference should contact: Madeline Pooley, Am Kavalleriesand 31, D-64295 Darmstadt, Germany (tel: +49 6151 807-606; fax: +49 6151807 612). (2/97)

\section{Call for Papers}

\section{2nd Annual Climate Diagnostics and Predic- tion Workshop, 6-10 October 1997, Berkeley, California}

The 22nd Climate Diagnostics and Prediction Workshop will be held 6-10 October 1997 in Berkeley, CA at the E. O. Lawrence Berkeley National Lab. The Workshop is cosponsored by the Climate Prediction Center, NCEP/NOAA, Washington, DC and the Program for Climate Model Diagnosis and Intercomparison, Lawrence Livermore National Lab., Univ. of California. The American Meteorological Society is a cooperating organization. The workshop will provide a forum to exchange ideas and viewpoints on a variety of climate topics.

Those interested in participating in the workshop should contact James D. Laver, acting director, CPC, W/NP5, Washington, DC 20233 (fax: 301-763-8395; e-mail: cdwshop@sgi85.wwb.noaa.gov) and should include the title, author(s), affiliation, a brief abstract, contact information (e-mail, phone, fax), and an indication of preference for oral or poster presentation, no later than 27 June 1997. (2/97; r3/97)

\section{Call for Papers}

\section{0th Conference on Applied Climatology, 20- 24 October 1997, Reno, Nevada}

The10th Conference on Applied Climatology sponsored by the American Meteorological Society and organized by the AMS Committee on Applied Climatology will be held 20-24 October 1997 at the Silver Legacy Hotel in Reno, Nevada.

Papers were solicited on all aspects of Applied Climatology, in particular, on the following themes: 1) climate impacts and interactions, particularly the application of climate change scenarios or analysis of extreme events and their impacts on human health, agricultural, forestry, or other biophysical systems, and socioeconomic systems; 2) the use of climate information for risk assessment, management and decision making, particularly as it relates to extreme events or potential climate change; 3 ) the value of climate information in business, legal and other societal settings; 4) the development, integration, and exchange of climate datasets, including the use of satellite-derived datasets in climatological analysis; and 5) the spatial and temporal accuracy and continuity of climate data, with special emphasis on derived products.

The deadline for abstracts has passed. The abstracts will be reviewed and disposition notices will be sent to all contributors. AMS will provide instructions to authors of accepted abstracts. Complete, camera-ready manuscripts (page length to be determined at a later date), including photos and diagrams, must be submitted not later than 1 July 1997 to AMS Headquarters. 
Page charges and any additional charges for photo processing will be assessed to defray printing costs. A preprint volume will be included with registration and available for purchase after the meeting.

For further information, contact David R. Easterling, NOAA/NCDC, 151 Patton Avenue, Asheville, NC 28801 (tel: 704-271-4311, fax: 704-271-4328; e-mail: deasterl@ncdc.noaa.gov). (6/96; r9/96; r10/96;r4/97)

\section{Call for Papers}

Second International SRNWP Workshop on Nonhydrostatic Modelling, 27-29 October 1997, Offenbach, Germany

The Second International SRNWP Workshop on Nonhydrostatic Modelling will be held 27-29 October 1997, in Offenbach, Germany. The American Meteorological Society is a cooperating organization.

The aim of the workshop is to be a forum of information concerning all questions of fine scale modelling. Contributions are invited showing the state of fine scale modelling. This includes work on basic equations, numerical methods, analysis, physics, numerical experimentation, and physiographic data. Applications range from numerical forecasting to scientific applications. Contributors are requested to submit an abstract of not more than one page by 30 June 1997 to J. Steppler, Duetscher Wetterdienst, Frankfurterstr 135, 63067 Offenbach, Germany (fax: 496982361493). (4/97)

\section{First International Conference on Reanalyses, 27-} 31 October 1997, Silver Spring, Maryland

The First International Conference on Reanalyses will be held 27-31 October 1997, Silver Spring, Maryland. The American Meteorological Society is a cooperating organization.

The primary objective of the conference is to present the results of the reanalysis projects undertaken by several groups over the past few years. Major efforts in this respect include the reanalyses by the ECMWF, NOAA, NCEP, NCAR, NASA, GSFC, and DAO.

Pleae contact the GEWEX Project Office for additional information on abstract topics. The deadline for abstracts has passed. For further information, contact International GEWEX Project Office, 1100 Wayne Ave., Suite 1210, Silver Spring, MD 20910 (tel: 301-427-2089, ext. 33; fax: 301-427-2222; e-mail: gewex@cais.com). $(1 / 97 ; \mathrm{r} 4 / 97)$

\section{The Physics of Climate, 29-30 October 1997, London, England}

The Physics of Climate, an international conference organized by the Royal Meteorological Society and supported by the Institute of Physics, will be held at the Royal Society, 29-30 October, London, England.
The American Meteorological Society is a cooperating organization.

The program will feature talks by eminent international speakers. Confirmed acceptances include John Houghton (IPCC), Edward Lorenz (MIT), Richard Goody (Harvard), Carl Wunsch (MIT), Graeme Stephens (Colorado State), Dennis Hartmann (Washington), Robert Charlson (Washington), John Monteith (ITE), John Mitchell (Hadley Centre), and Brian Hoskins (Reading).

The deadline for abstracts has passed. For further technical information please contact the Royal Meteorological Society, 104 Oxford Road, Reading, Berkshire RG1 7LL, UK (tel: +01189 568500; fax: +01189 568571; e-mail: execsec@royal-met-soc.org.uk). $(4 / 97)$

\section{Call for Papers}

First International Conference on Asian Monsoon and Pollution over the Monsoon Environment, 25 December 1997, New Delhi, India

First International Conference on Asian Monsoon and Pollution over the Monsoon Environment, sponsored by the Indian Meteorological Society and cosponsored by the American Meteorological Society and the World Meteorological Organization, will be held 2-5 December 1997 at New Delhi, India.

The topics to be covered will include observational and modeling studies of the monsoon from days to decades. Of interest will also be pollution studies from local to planetary scales. Chemical transport issues related to pollution will also be covered.

Participation from India, the United States, and a wider international community is planned for the conference.

Both oral and poster presentations are encouraged at this meeting. Interested scientists are encouraged to submit a title and abstract to one of the cochairpersons listed below. Abstracts of no more than one page in length should be submitted by 1 June 1997. It should include the name of the author(s), affiliation, address, telephone and fax numbers, and e-mail addresses. Authors should also indicate their preferences for oral or poster presentation.

For further information contact one of the conference cochairpersons: T. N. Krishnamurti, Deptartment of Meteorology, Florida State University, Tallahassee, FL 32306-3034 (tel: 904-644-2210; fax: 904-644-9642) or R. K. Datta, 48 A, Pkt. C, Gangotri Enclave, Alaknanda, New Delhi-1100019, India (tel: 91-11-6448155; fax: 9111-4699216). (8/96; r1/97) 
78th AMS Annual Meeting, 11-16 January 1998, Phoenix, Arizona

The 78th Annual Meeting of the American Meteorological Society will be held in Phoenix, Arizona, 1116 January 1998 . To date the following short courses, conferences, symposia, and special sessions have been scheduled: Short Course on Mountain Meteorology, Short Course on Air Pollution, 16th Conference on Weather Analysis and Forecasting and 12th Conference on Numerical Weather Prediction, 14th International Conference on Interactive Information and Processing Systems (IIPS) for Meteorology, Oceanography, and Hydrology, 14th Conference on Probability and Statistics in the Atmospheric Sciences, 10th Joint Conference on the Applications of Air Pollution Meteorology with the Air \& Waste Management Association (A\&WMA), 10th Symposium on Meteorological Observations and Instrumentation, Ninth Symposium on Global Change Studies, Ninth Conference on Interaction of the Sea and Atmosphere, Seventh Symposium on Education, Second Symposium on Fire and Forest Meteorology, Second Symposium on Integrated Observing Systems, Second Conference on Coastal Atmospheric and Oceanic Prediction and Processes, First Conference on Artificial Intelligence, Symposium on Status and Prospects for Climate Prediction, Symposium on The Research Foci of the U.S. Weather Research Program, and a Special Session Honoring the Centennial of the Birth of CarlGustaf A. Rossby.

AMS will continue its popular commercial exhibit and book and CD-ROM exhibit at the 78th AMS Annual Meeting. If you are interested in exhibiting, please contact Monica Tolson (tel: 202-682-9006, e-mail: tolson@dc.ametsoc.org) for additional information, reservations, and a contract. (11/96; r12/96)

\section{Announcement}

\section{AMS Short Course on Mountain Meteorology, 10- 11 January 1998, Phoenix, Arizona}

An AMS Short Course on Mountain Meteorology, sponsored by the American Meteorological Society and organized by the AMS Committee on Mountain Meteorology, will be held 10-11 January 1998 preceding the 78th AMS Annual Meeting in Phoenix, Arizona.

The two-day short course is designed for meteorologists and students interested in mountain weather phenomena and the applications of mountain weather knowledge to a variety of practical problems.

The course is intended for the non-specialist, and will deal broadly with mountain meteorology topics including observations, analysis, and modeling. It will be taught by prominent mountain meteorologists who will provide 45 to 60 minute talks in their areas of expertise. Ample time will be allowed for comments and discussion.

Fundamentals of mountain meteorology will be the theme of the first days presentations, which will include talks on influence of mountains on larger-scale flows, interactions of fronts with topography, mountain waves and wakes, and thermally driven mountain wind systems.

Observations and applications of mountain meteorology will be the theme for the second day, with presentations on recognition of mountain weather phenomena, mountain weather forecasting, air pollution dispersion, fire weather and smoke management, and mountain hydrology applications.

For additional technical information, please contact Teddie L. Keller, National Center for Atmospheric Research (NCAR), Research Applications Program, P.O. Box 3000, Boulder, CO 80303 (tel: 303-497-8428; fax: 303-497-8401; e-mail: tkeller@ncar.ucar.edu). $(4 / 97)$

\section{Announcement}

\section{AMS Short Course on Air Pollution, 11 January 1998, Phoenix, Arizona}

A one-day Short Course on Air Pollution Meteorology, sponsored by the American Meteorological Society and organized by the AMS Committee on Meteorological Aspects of Air Pollution and the AMS Board of Private Sector Meteorology, is planned for Sunday, 11 January 1998. Virginia Bigler-Engler of the San Diego County Air Pollution Control Board will be the chairperson of this short course. Further details will be printed in a future edition of the Bulletin. (3/97)

\section{Call for Papers}

16th Conference on Weather Analysis and Forecasting and 12th Conference on Numerical Weather Prediction, 11-16 January 1998, Phoenix, Arizona

The 16th Conference on Weather Analysis and Forecasting and 12th Conference on Numerical Weather Prediction will be jointly held during the 1998 AMS Annual Meeting, 11-16 January 1998 in Phoenix, Arizona. The conference is sponsored by the American Meteorological Society and organized by the AMS Committee on Weather Analysis and Forecasting.

The joint conference will focus on small-scale, high frequency phenomena and short-term prediction. This is a much narrower focus than past conferences. Only abstracts that pertain to the focus of the conference will be accepted (with the exception below). Another conference planned for a later date will focus on largerscale, lower frequency phenomena and longer-term forecasts. Joint sessions are anticipated with the concurrent Symposium of the United States Research Program, 
to be convened by the AMS Committee on Mesoscale Processes. The topics for the joint sessions will be quantitative precipitation forecasting, the optimal mix of observations for improving forecasts, and landfalling tropical cyclones. Additionally, there will be joint sessions that include the14th Conference on Probability and Statistics. The topics here will be verification procedures, techniques, and results, with particular emphasis on the societal and economic value of weather forecasts. Because of their general nature, papers addressing these topics can extend to medium-range ( $<$ two weeks) predictions and applications.

Please submit your one page abstract by 1 July 1997 to Norman W. Junker at the address listed below. AMS will provide instructions to authors of accepted abstracts. Complete camera-ready manuscripts (page length to be determined at a later date), including photos and diagrams must be submitted to AMS Headquarters by 1 October 1997. Page charges and any additional charges for photo processing will be assessed to defray printing costs. Registrants will receive a preprint volume at the conference.

For further information contact, Norman W. Junker (tel: 301-763-8201) or Paul Kocin (301-763-8077 ext. 7356; fax: 301-763-8085), Hydrometeorological Prediction Center, NCEP, 5200 Auth Rd., Rm 410, Camp Springs, MD 20746. (12/96; r1/97; r3/97; r4/97; r5/97)

\section{Call for Papers}

\section{Special Sessions on Tropical Cyclone Intensity Change, 11-16 January 1998, Phoenix, Arizona}

Special sessions on Tropical Cyclone Intensity Change will be held as part of the 16th Conference on Weather Analysis and Forecasting at the AMS Annual Meeting in Phoenix, Arizona, 11-16 January 1998.

The sessions are jointly sponsored by the AMS Committees on Tropical Meteorology and Tropical Cyclones, and Weather Analysis and Forecasting, and will run for one afternoon and the entire following day.

These sessions are intended to promote wide-ranging discussions on competing theories of the life cycle evolution of tropical cyclone intensity, as well as current forecasting and research issues relating to this problem, and will comprise a mix of invited and submitted papers and posters. A format designed to maximize opportunities for discussion will be attempted following the first afternoon's session. Individual portions of the sessions will center around a selected theory of tropical cyclone intensity change.

Please send abstracts (including corresponding author's complete mailing and email address) by 1 July 1997 to Hugh Willoughby, Hurricane Research Division/ AOML/NOAA, 4301 Rickenbacker Cswy, Miami, FL 33143-1026 (fax: 305-361-4402).
For information contact either: Jenni Evans (e-mail: evans@essc.psu.edu) or Hugh Willoughby (e-mail: eillough@aoml.noaa.gov). (5/97)

\section{Call For Papers}

\section{4th International Conference on Interactive Information and Processing Systems (IIPS) for Meteorology, Oceanography, and Hydrology, $11-$ 16 January 1998, Phoenix, Arizona}

The 14th International Conference on Interactive Information and Processing Systems (IIPS) for Meteorology, Oceanography, and Hydrology, sponsored by AMS, will be held as a part of the 78th AMS Annual Meeting, 11-16 January 1998 in Phoenix, Arizona. The theme for the 1998 meeting is "The Maturing of Our Predictive Capability."

This applied interactive technology conference brings together the government, academia, and private sectors, both international and national, and those who supply or use data and information systems and technology. Preliminary IIPS sessions are planned for interdisciplinary applications, status of modernization activities of government and commercial weather services, technology and technique development at laboratories and in industries associated with meteorology, hydrology and oceanography, and applications of IIPS using radar, satellites, other observation platforms, and their associated data processing systems.

Special sessions are also planned on the NOAA Satellite Program (including the geostationary and polar satellites), applications of decision support tools in aviation weather, hydrology and water qulaity, metadata, U.S. Air Force Systems, NEXRAD product improvement, the overall economic benefits of weather information. and the use and leverage of the Internet. A special session is planned on the topic of water quantity and quality, drawing on speakers familiar with water prediction and planning for the southwest United States and other regions that are shepherding their weather resources.

Joint sessions are tentatively planned with the Conference on Weather Analysis and Forecasting and a triconference joint session that includes the IIPS Surface Transportation and the Environment, the 2nd Symposium on Integrated Observing Systems, and the 10th Symposium on Meteorological Observations and Instrumentation. International aspects of IIPS will apply to most of these topic areas but a special session will feature European applications. The IIPS session on surface transportation and the environment will address all facets and impacts of the natural environment on road, rail, and waterway modes of transportation. Subjects will range from observing systems, communication systems, analysis and forecasting systems, dissemination systems to special services needed to serve the surface transpor- 
tation industry, including transportation management centers and traffic flow control. Although the focus will be on road weather, papers are invited to include air and water quality monitoring and mitigation related specifically to surface transportation infrastructure and operations. Officials from the Center for Transportation Studies, American Society for Testing and Materials and Electrical Manufacturers Association will participate in this session.

Primary contact for the Surface Transportation session is Stan Doore at 2193 Shanandale Dr., Silver Spring, MD 20904-1822 (tel: 301-572-4939; fax: 301572-9165; e-mail: stan.doore@mix.cpcug.org). If you need more information about the other topics listed or about the key contacts please contact either of the conference cochairpersons as shown in the final paragraph.

The deadline for abstracts is 1 July 1997. AMS will provide instructions to authors of accepted abstracts. Complete camera-ready manuscripts (page length to be determined at a later date), including photos and diagrams, must be received at AMS Headquarters by 1 October 1997. Page charges and any additional charges for photo processing will be assessed to defray printing costs. Registrants will receive a preprint volume at the conference.

The conference will include exhibits and demonstrations that continue to be popular and help to illustrate the practicality of using off-the-shelf, demonstrated marketable systems and software tailored to meet the needs of meteorology, oceanography, and hydrology. Potential exhibitors should contact Yale Schiffman, exhibits manager, American Meteorological Society, 1200 New York Avenue, Suite 410, Washington, DC 20005 (tel: 202-682-9006; fax: 202-682-9341).

The IIPS Program Committee encourages authors to use computers and video equipment in support of their oral and poster presentations. Large-screen projection systems for data and video presentations will be available during the conference. There will also be access to a T1 Internet line for support of oral and poster presentations.

For more detailed information and audio/visual aids, available computer equipment, and suggestions for your presentations please consult the AMS Home Page (http:// ametsoc.org/AMS). For further information, contact one of the conference cochairpersons: Floyd F. Hauth, National Weather Service Modernization Committee, HA 278, National Research Council, 2101 Constitution Avenue NW, Washington, DC 20418 (tel: 202-3342856; fax:202-334-3819; e-mail: fhauth@ nas.edu) or Joseph S. Matney, The MITRE Corporation, 1820 Dolly Madison Blvd., McLean, VA 22120 (tel: 703-883-6942; fax: 703-883-6478; e-mail: jmatney@ mitre.org). (12/96; r5/97)

\section{Call For Papers}

14th Conference on Probability and Statistics in the Atmospheric Sciences, 11-16 January 1998, Phoenix, Arizona

The 14th Conference on Probability and Statistics in the Atmospheric Sciences, sponsored by the American Meteorological Society and organized by the AMS Committee on Probability and Statistics, will be held as part of the 78th AMS Annual Meeting, 11-16 January 1998, in Phoenix, Arizona.

High quality papers are solicited on all aspects of probability and statistics which have applications in the atmospheric sciences. Review papers that emphasize recent advances and future opportunities in probability and statistics will also be considered. Joint sessions will be organized in conjunction with several other conferences taking place concurrently at the AMS Annual Meeting. These sessions will include one focusing on extreme events (jointly sponsored by the Ninth Symposium on Global Change Studies). Two other joint sessions, co-sponsored by the Conference on Weather Analysis and Forecasting and Numerical Weather Prediction, will concern topics related to the theme of the AMS Annual Meeting ("The Maturing of Our Predictive Capability"). These sessions will be 1) on the economic and societal value of short-to-medium range forecasts and 2) on the evolution of the quality of weather forecasts. Papers on these topics are especially solicited. A workshop will be held the weekend prior to the conference on a probability and statistics topic of current interest in the atmospheric sciences.

Acceptance of papers will be based on a reviewer's abstract, a 300-500 word synopsis of the proposed paper, which should discuss the primary methods and their relevance to specific problems in the atmospheric sciences. When submitting abstracts, authors should indicate their preference for either an oral or poster presentation. Every effort will be made to assign papers to sessions according to the format requested by the author. Authors also should indicate if their paper is especially intended for one of the joint sessions identified above.

Authors wishing to contribute papers to this conference should submit their abstract to Barbara G. Brown at the address below by 1 July 1997. Please provide complete mailing and e-mail addresses, plus telephone and fax numbers. AMS will provide instructions to authors of accepted abstracts. Complete camera-ready manuscripts (page length to be determined at a later date), including photos and diagrams, must be received at AMS Headquarters by 1 October 1997. Page charges and any additional charges for photo processing will be assessed to defray printing costs. Registrants will receive a preprint volume at the conference. 
For additional information, contact Barbara G. Brown, NCAR, P.O. Box 3000, Boulder, CO 80307-3000 (tel: 303-497-8468; fax: 303-497-8401; e-mail: bgb@ncar.ucar.edu) (12/96; 5/97)

\section{Call For Papers}

\section{0th Joint Conference on the Applications of Air Pollution Meteorology with the Air \& Waste Man- agement Association (A\&WMA), 11-16 January 1998, Phoenix, Arizona}

The 10th Joint Conference on the Applications of Air Pollution Meteorology with the Air \& Waste Management Association, sponsored by the American Meteorological Society and organized by the AMS Committee on Meteorological Aspects of Air Pollution (CMAAP), will be held as a part of the 78th AMS Annual Meeting, 11-16 January 1998 in Phoenix, Arizona. The meeting will be cosponsored by the Meteorology Committee (AB-3) of the Air \& Waste Management Association (A\&WMA).

Both poster and oral presentations are solicited in all areas of air pollution meteorology. It is expected that sessions will be held covering the following topics: 1) modeling of accidental releases of air toxics, 2) complex flows affecting dispersion near obstacles and within urban environments, 3) coastal and complex terrain issues, 4) the role of air pollution modeling in integrated assessments, 5) regional-scale transport and photochemical modeling, 6) visibility and deposition modeling issues, 7) advanced dispersion modeling techniques, 8) field studies and model evaluation projects, 9) parameterization of the planetary boundary layer, and 10) emissions modeling systems and emissions estimation from remote-sensing techniques.

A 1- or 2-day short course on aspects of meteorology and air quality dispersion modeling is planned in conjunction with the AMS Annual Meeting; more information will be forthcoming. A special issue of the Journal of Applied Meteorology will be published sometime after the meeting that contains papers submitted by authors presenting papers at the conference.

Abstracts (including title, authors, and a description of the paper not exceeding about 300 words) are required by 1 June 1997 and should be sent by mail or by fax to Robert J. Paine, ENSR Corporation, 35 Nagog Park, Acton, MA 01720 (tel: 508-266-4164; fax: 508-6359180 ). Authors should provide complete mailing and email addresses, plus telephone and fax numbers. AMS will provide instructions to authors of accepted $a b-$ stracts. Complete, camera-ready manuscripts (page length to be determined at a later date) including photos and diagrams must be submitted no later than 1 October 1997 to AMS Headquarters. Page charges and any additional charges for photo processing will be as- sessed to defray printing costs. Registrants will receive a preprint volume at the conference.

For further information, contact the Program Cochairpersons, Robert J. Paine at the above address or Mark V. Carney, U.S. Generating Company, 7500 Old Georgetown Road, Bethesda, MD 20814 (tel: 301-7186899; fax: 301-718-6917). (12/96)

\section{Call For Papers}

\section{0th Symposium on Meteorological Observations and Instrumentation, 11-16 January 1998, Phoenix, Arizona}

The 10th Symposium on Meteorological Observations and Instrumentation, sponsored by the American Meteorological Society and organized by the AMS Committee on Measurements, will be held as a part of the 78th AMS Annual Meeting, 11-16 January 1998 in Phoenix, Arizona.

Presentations are solicited on all aspects of atmospheric measurements (in situ and remote), observations, quality control and assurance, instrumentation technologies, and models of sensor performance, network design, and sampling strategies. Both research and operational instrumentation and measurement techniques are welcome.

Areas of emphasis include automated weather observations and their ability to obtain accurate information, evolving technologies and applications of the Global Positioning System, standards and methods of observations for power plants and other fixed facilities, surface radiation measurements, observations of water vapor profiles, and surface and ground-based remote sensing techniques to infer areal averages of surface energy budgets.

Titles and abstracts of no more than one page are due by 1 July 1997 to Marvin L. Wesely at the address below. Please include at the top of each abstract the author's name, affiliation, complete mailing address, telephone and fax numbers, and e-mail address. Also indicate the name and affiliation of each coauthor under the title. Authors of accepted papers will be notified by 1 August 1996.

Complete camera-ready manuscripts (page length to be determined at a later date), including photos and diagrams, must be submitted no later than 1 October 1997 to AMS Headquarters. Page charges and any additional charges for photo processing will be assessed to defray printing costs. Registrants will receive a preprint volume at the conference.

For further information contact Marvin L. Wesely, Building 203, Environmental Research Division, 9700 S. Cass Ave., Argonne National Laboratory, Argonne, IL 60439 (tel: 630-252-5827; fax: 630-252-5498; e-mail: mlwesely@anl.gov). (12/96) 


\section{Call For Papers}

\section{Ninth Symposium on Global Change Studies, 11 - 16 January 1998, Phoenix, Arizona}

The Ninth Symposium on Global Change Studies, sponsored by the American Meteorological Society, will be held as part of the 78th AMS Annual Meeting, 1116 January 1998 in Phoenix, Arizona. Papers are solicited on all aspects of global change.

Sessions are encouraged in the following areas: 1) detection and attribution of global change; 2) global system modeling, especially results from coupled models and long simulations; 3 ) impacts of global change on man and the environment; 4) the hydrological cycle, including observed changes; 5) the role of the oceanatmosphere fluxes in decadal-to-century-scale global change, including ENSO and the North Atlantic Oscillation; 6) global change in the context of extreme events; and 7) climate prediction. Possible joint sessions with other conferences, such as Probability and Statistics (regarding extreme events and detection issues) and Interaction of the Sea and Atmosphere are examples. Authors of papers that would like to be considered for joint sessions should specifically indicate their preference, and a decision will be made by the organizing committees as to the feasibility of joint sessions.

One-page abstracts must be submitted by 1 July 1997 to Thomas R. Karl at the address below. Please include at the top of each abstract the author's name, affiliation, complete mailing address, telephone, fax number, and e-mail address. AMS will provide instructions to authors of accepted papers. This will serve as your notice of acceptance. Complete, camera-ready manuscripts (page length to be determined at a later date), including photos and diagrams, must be submitted no later than 1 October 1997 to AMS Headquarters. Page charges and any additional charges for photo processing will be assessed to defray printing costs. Registrants will receive a preprint volume at the conference.

For further information, contact the program chair, Thomas R. Karl, NOAA/National Climatic Data Center, 151 Patton Avenue, Asheville, NC 28801-5001 (fax: 704-271-4319; e-mail: tkarl@ncdc.noaa.gov). (12/96)

\section{Gall For Papers}

\section{Ninth Conference on Interaction of the Sea and Atmosphere, 11-16 January 1998, Phoenix, Arizona}

The Ninth Conference on Interaction of the Sea and Atmosphere, sponsored by the American Meteorological Society and organized by the AMS Committee on Interaction of the Sea and Atmosphere, will be held as part of the 78th AMS Annual Meeting, 11-16 January 1998 in Phoenix, Arizona.
The conference will address air-sea interactions on multiple scales. Results of observational and modeling studies are of interest. Papers are solicited on all aspects of interactions of the sea and atmosphere, such as 1) influence of freshwater flux and salinity on simulations of sea surface temperature; 2) contributions of the tropical Pacific ocean-atmosphere in situ and satellite observations on seasonal-to-interannual predictions; 3) air-sea interactions in the warm water pool in the eastern Indian Ocean and western Pacific Ocean; 4) air-sea interactions, North American monsoon, and predictability of warm season climate anomalies; 5) parameterization of subgrid-size scale air-sea interactions in general circulation models; 6) simulations of oceanographic and atmospheric variables from coupled ocean-atmosphere general circulation models; 7) airsea interactions and the North Atlantic Oscillation; and 8) new results from NSCAT.

A one-page abstract must be submitted by 1 July 1997 to David Halpern at the address below. Only one abstract per speaker. At the top of the abstract, provide the author's name, affiliation, complete mailing address, telephone and fax numbers, and e-mail address. AMS will provide instructions to authors of accepted papers. Complete camera-ready manuscripts (page length to be determined at a later date) must be submitted to AMS Headquarters by 1 October 1997. Page charges and any additional charge for photo processing will be assessed by AMS to defray printing costs. Registrants will receive a preprint volume at the conference.

For further information, contact the Program Chairperson, David Halpern, Jet Propulsion Laboratory, M/S 300-323, California Institute of Technology, Pasadena, CA 91109-8099 (tel: 818-354-5327; fax: 818-393-6720; e-mail: halpern@pacific.jpl.nasa.gov). (12/96)

\section{Gall For Papers}

\section{Seventh Symposium on Education, 11-16 January 1998, Phoenix, Arizona}

The Seventh AMS Symposium on Education, sponsored by the American Meteorological Society, will be held in conjunction with the 78th AMS Annual Meeting, 11-16 January 1998 at the Phoenix Convention Center in Phoenix, Arizona. Jointly organized by the Board on School and Popular Meteorological and Oceanographic Education and the Board on Meteorological and Oceanographic Education in Universities, the theme of the symposium will be "Atmospheric and Oceanic Education: Advancing our Awareness." Papers on topics relevant to $\mathrm{K}-12$ and college/university undergraduate and graduate education are invited. At the $\mathrm{K}-12$ level, papers are encouraged on precollege educational outreach programs throughout the atmospheric and oceanographic communities. Both papers and posters 
are requested. At the college/university session, there will be a special session on increasing diversity throughout the atmospheric and oceanic sciences, including efforts to promote representation of minorities in our respective disciplines. There will be also be a joint session with the 9th Conference on Interaction of Sea and Atmosphere and the 2nd Conference on Meteorology and Oceanography of the Coastal Zone. Papers with educational applications for these scientific areas are encouraged.

Abstracts should be sent by 1 June 1997 to the program cochairpersons. Authors of accepted papers will be notified by 1 July 1997. Camera-ready manuscripts (page length to be determined at a later date) must be received at AMS Headquarters no later than 1 October 1997 to be included in the preprint volume. Page charges and any additional charge for photo processing will be assessed to defray printing costs. Registrants will receive a preprint volume at the conference.

For further information, contact the Program Cochairpersons - David R. Smith (papers on K-12 topics or the joint session), Oceanography Department, United States Naval Academy, 572 Holloway Road, Annapolis, MD 21402 (fax: 410-293-2137) or Lisa Bastiaans (papers on college/university topics), Nassau Community College, Physical Sciences Dept., Garden City, NY 11530 (fax: 516-331-9646). Please send all abstracts via email to: DRSMITH@NADN.NAVY.MIL; include the following information: name, affiliation, complete mailing address, phone and fax numbers, and e-mail address. (12/96; r2/97;r3/97; r4/97)

\section{Gall for Papers}

\section{Second Symposium on Fire and Forest Meteorol- ogy, 11-16 January 1998, Phoenix, Arizona}

The Second Symposium on Fire and Forest Meteorology will be held 11-16 January 1998 as a part of the 78th AMS Annual Meeting in Phoenix, Arizona. The symposium is sponsored by the American Meteorological Society and organized by the AMS Committee on Agricultural and Forest Meteorology.

The primary objective of the symposium is to share recent experiences and new work and/or changes in the areas of 1) operational fire weather forecasting; 2) application of new technology to real-time fire weather forecasting; 3) fire behavior assessment and predictions; 4) micro- and mesoscale modeling related to fire behavior; 5) application of medium and long range forecasting to fire planning; and 6) use of weather information and forecasts in prescribed fire and/or prescribed natural fire.

Abstracts (maximum length one page) must be submitted by 1 July 1997 to the program cochairpersons listed below. Please include at the top of each abstract, the author's name(s), affiliation, complete mailing address, telephone and fax numbers, and e-mail address. AMS will provide instructions to authors of accepted abstracts. Complete camera-ready manuscripts (page length to be determined at a later date), including photos and diagrams, must be received at AMS Headquarters by 1 October 1997. Page charges and any additional charges for photo processing will be assessed to defray printing costs. Registrants will receive a preprint volume at the conference.

For additional information, please contact one of the Program Cochairpersons: Francis Fujioka, USDA/US Forest Service, 4955 Canyon Crest Drive, Riverside, CA 95207 (tel: 909-680-1552; fax: 909-680-1501; e-mail: f.fujioka/ou1=s27105a@mhs-fwsa.attmail.com) or David Goens, NOAA/National Weather Service, 1320 Beechcraft, Pocatello, ID 83201 (tel: 208-232-9306; fax: 208-233-2471, e-mail: dgoens@pih.noaa.gov). $(12 / 96)$

\section{Call for Papers}

\section{Second Symposium on Integrated Observing} Systems, 11-16 January 1998, Phoenix, Arizona

The Second Symposium on Integrated Observing Systems, sponsored by the American Meteorological Society, will be held 11-16 January 1998 as part of the 78th AMS Annual Meeting in Phoenix, Arizona. Advances in both understanding and prediction depend upon high-quality observations. A wide range of scientific problems and environmental issues, including weather and flood warnings; atmospheric predictions on all time and space scales; understanding ocean processes and the interaction between the ocean and atmosphere; climate modeling; and many others require complex and costly observational systems. Despite the wide range of time and space scales targeted by different observing systems, they share many similarities and often systems designed for one purpose are well suited for another. This symposium is intended to provide opportunities for exploring observational needs, data assimilation and analysis methods and integrating observing strategies to serve multiple purposes.

The program of the 78th AMS Annual meeting emphasizes our weather prediction ability. The Symposium on Integrated Observing Systems will reflect this emphasis and its primary focus will be on systems to meet the needs of weather prediction at all time and space scales including oceanographic and hydrological aspects, although contributions for systems needed to understand, assess and predict climate change are also solicited. A focus will also be on systems required for the study of air-sea interactions.

The Second Symposium on Integrated Observing Systems cuts across virtually all of the other conferences 
and symposia being held in conjunction with the 78th AMS Annual Meeting. Therefore, sessions on the following are being considered: North American Atmospheric Observing System (in cooperation with 16th Conference on Weather Analysis and Forecasting); integrated ocean observing systems (in cooperation with the Ninth Conference on Interaction of the Sea and Atmosphere), the Integrated Global Observing Strategy and the Global Climate, Ocean and Terrestrial Observing Systems; data assimilation in models, its integrating role on all time and space scales; integration of observations from radar, satellite and other remote sensing technologies; local and mesoscale observing systems; Hydrology (in cooperation with the AMS Committee on Hydrology); and meteorological applications deriving from integrated environmental monitoring networks. Cooperative activities will also be undertaken with the 10th AMS Symposium on Meteorological Observations and Instrumentation.

Abstracts of no more than 1 page will be due by 1 July 1997. Authors of accepted papers will be notified by 1 August 1997. Papers intended for joint sessions should be designated as such and will be coordinated with the chairpersons of the other conferences and symposia. AMS will send instructions to authors of accepted abstracts. Camera-ready manuscripts (page length to be determined at a later date), including photos and diagrams, must be submitted no later than 1 October 1997 to AMS Headquarters. Page charges and any additional charges for photo processing will be assessed to defray printing costs. Registrants will receive a preprint volume at the conference.

For further information, contact one of the symposium chairs: James Rasmussen, Office of Oceanic and Atmospheric Research, Environmental Research Lab., 1315 East-West Highway, Room 11618, Silver Spring, MD 20910 (tel: 301-713-2458; fax: 301-713-0163; email: jrasmussen@oar.noaa.gov); or Otis Brown, RSMAS, Univ. of Miami, 4600 Rickenbacker Cswy., Miami, FL 33149-1098 (tel: 305-361-4000; fax: 305-3614711; e-mail: obrown@rsmas.miami.edu). (12/96)

\section{Gall for Papers}

\section{Second Conference on Coastal Atmospheric and Oceanic Prediction and Processes, 11-16 January 1998, Phoenix, Arizona}

The Second Conference on Coastal Atmospheric and Oceanic Prediction and Processes, will be held as a part of the 78th AMS Annual Meeting, 11-16 January 1998 in Phoenix, Arizona. The conference is sponsored by the American Meteorological Society and organized by the AMS Committee on Meteorology and Oceanography of the Coastal Zone and the AMS Committee on Interaction of the Sea and Atmosphere.
The purpose of this conference is to strengthen the scientific and technical communications between meteorologists and physical oceanographers involved in this topic area, from research and operational perspectives, at a time when both NOAA (NWS, NOS, and OAR) and the Navy (ONR and CNMOC), and their European and Asian counterparts, are continuing pioneering $R \& D$ and operational steps in the direction of coastal atmospheric and oceanic prediction. Thus, as the second conference on this topic, the hope is that it will serve to build further a community of involved and interacting scientists and stimulate further progress.

The conference will address research, development, and operational issues and activities bearing on the prediction of coastal atmospheric and oceanic prediction and weather. Here, "coastal" pertains to the domain \pm ca. $300 \mathrm{~km}$ from the coastline, and "prediction" encompasses simulation as well as hindcasting, nowcasting, and forecasting. Process studies as well as observing, modeling, and data assimilation systems will be addressed. In particular, the utilization of satellite, coastal radar, and other remote sensing systems is of interest. Papers on environmental and societal applications, plus value-added industry opportunities, are solicited.

Please send abstracts by 1 July 1997 to the program chairperson listed below. AMS will provide instructions to authors of accepted abstracts. Complete camera-ready manuscripts (page length to be determined at a later date), including photos and diagrams, must be received at AMS Headquarters by 1 October 1997. Page charges and any additional charges for photo processing will be assessed to defray printing costs. Registrants will receive a preprint volume at the conference.

For further information, contact the program chairperson: C. N. K. Mooers, University of Miami, RSMAS, 4600 Rickenbacker Causeway, Miami, FL 33149-1098 (tel: 305-361-4825; fax: 305-361-4797; e-mail: cmooers@rsmas.miami.edu). (12/96)

\section{Call for Papers}

\section{First Conference on Artificial Intelligence, 13-} 14 January 1998, Phoenix, Arizona

The First AMS Conference on Artificial Intelligence, sponsored by the American Meteorological Society and organized by the AMS Committee on Artificial Intelligence, will be held as part of the 78th AMS Annual Meeting in Phoenix, Arizona, 13-14 January 1998.

The central theme of the conference is the application of artificial intelligence techniques in the weather forecast office, and as a research tool in meteorology, oceanography, climatology and hydrology. Such techniques include (but are not limited to) expert systems, artificial neural networks, machine learning, and cognitive task analysis. 
Those who are interested in presenting papers are requested to submit an abstract of 200 words or less (with corresponding author's complete mailing address, telephone and fax numbers and e-mail address) to Rosemary M. Dyer, PL/GPAB, 29 Randolph Road, Hanscom AFB, MA 01731-3010 (tel: 617-377-2967;fax: 617377-2984; e-mail: dyer@plh.af.mil) or by interactive web server at http://colossus.plh.af.mil:88/submit.html by 1 July 1997. Please indicate if you have a preference regarding oral or poster presentation. AMS will provide instructions to authors of accepted abstracts. Complete camera-ready manuscripts (page length to be determined at a later date), including photos and diagrams, must be received at AMS Headquarters by 1 October 1997. Page charges and any additional charges for photo processing will be assessed to defray printing costs. Registrants will receive a preprint volume at the conference. For further information, contact the program chairperson at the above address. (12/96)

\section{Symposium on Status and Prospects for Climate Prediction, 11-16 January 1998, Phoenix, Arizona}

A one-day Symposium on Status and Prospects for Climate Prediction, sponsored by the American Meteorological Society, will be held as a part of the 78th AMS Annual Meeting, 11-16 January 1998, Phoenix, Arizona. This symposium is organized by the AMS Committee on Climate Variations and the AMS Committee on Societal Impacts, and cosponsored by the Symposium on Global Change Studies.

Invited talks at the symposium will address the broad spectrum of climate prediction issues-programmatic developments, scientific approaches and results, and the estimation of socioeconomic value. The symposium will support the annual meeting theme, "The Maturing of Our Atmospheric Prediction Capability." It is anticipated that speakers will include international participants. Sessions on climate prediction are also being planned by the Ninth Symposium on Global Change Studies, and prospective authors are invited to submit papers to that symposium.

For further information, please contact Peter J. Lamb, CIMMS/University of Oklahoma, 100 East Boyd St., Rm. 1310, Norman, OK 73019-0628 (tel: 405-325-3041; fax: 405-325-7614; e-mail: plamb@uoknor.edu). (12/96)

\section{Gall For Papers}

\section{Symposium on The Research Foci of the U.S. Weather Research Program, 1 1-16 January 1998, Phoenix, Arizona}

A one-day Symposium on The Research Foci of the U.S. Weather Research Program (USWRP), sponsored by the American Meteorological Society, will be held as a part of the 78th AMS Annual Meeting in Phoenix, Arizona, 11-16 January 1998.
The symposium will be organized by the AMS Committee on Mesoscale Processes and will include both invited and submitted papers. Authors are requested to report upon current research findings consistent with the near-term research foci of the USWRP including their perceptions of future research required to advance understanding and improve prediction of weather systems. The symposium sessions and near-term USWRP research foci are Session I: The Importance and Mix of Observations; Session II: Quantitative Precipitation Forecasting; and Session III: Hurricane Forecasting.

The symposium is intended to serve as the first overview of the current state-of-the-science for the proposed research foci, as well as providing a venue for airing further recommendations for present and future directions of the USWRP. The Symposium will be limited to five invited lectures and 15 submitted papers $(20 \mathrm{~min}$ utes). There will be no poster presentation session. Presenters are requested to prepare written versions of their oral presentations for inclusion in the symposium preprint volume.

Deadline for abstracts has passed. Authors of accepted and deferred papers will be notified by 1 June 1997. Those papers not accepted for presentation will be forwarded by the program cochairpersons to one of the other relevant symposia at the Annual Meeting. AMS will provide instructions to authors of accepted papers. Complete camera-ready manuscripts, (page length to be determined at a later date), including photographs and diagrams, must be received at AMS Headquarters no later than 1 October 1997. Page charges and any additional charges for photo processing will be assessed to defray printing costs. Registrants will receive a preprint volume at the conference.

For further information, contact one of the program cochairpersons: Melvyn A. Shapiro, USWRP/Symposium, NOAA/Environmental Technology Laboratory, 325 Broadway, Boulder, CO 80303 (tel: 303-497-6962; fax: 303-497-6978; e-mail: mshapiro@etl.noaa.gov) or Robert Gall, USWRP/Symposium, NCAR/MMM, P.O. Box 3000, Boulder, CO 80307-3000 (tel: 303-4978160; fax: 303-497-8181; e-mail: gall@ncar.ucar.edu). $(12 / 96 ; \mathrm{r} 1 / 97 ; \mathrm{r} 5 / 97)$

\section{Announcement}

\section{Special Session Honoring the Centennial of the Birth of Carl-Gustaf A. Rossby, January 1998, Phoenix, Arizona}

AMS would like to recognize the centennial birth of Carl-Gustaf A. Rossby by holding a special session at the 78th AMS Annual Meeting in Phoenix, Arizona, 11-16 January 1998. Further details will be published in a future issue of the Bulletin. (1/97) 


\section{Call For Papers}

1998 Ocean Sciences Meeting, 9-13 February 1998, San Diego, California

1998 Ocean Sciences Meeting, sponsored by the American Geophysical Union (AGU) and the American Society of Limnology and Oceanography (ASLO), will be held 9-13 February 1998 in San Diego, California. The American Meteorological Society is a cooperating organization.

This meeting is designed specifically to meet the needs of oceanographers, limnologists, meteorologists, and scientists working in related areas. Subdisciplines for this meeting are atmospheric sciences, estuarine sciences, limnology, oceanography, and ocean technology.

Contributed papers in the following areas, and any related topics, are encouraged: physics of the oceans and climate; large-scale transport and circulation; biogeochemical processes; land-sea interactions; ocean optics; polar oceanography; near-shore sediment transport and shelf sedimentation; planktonic and benthic food webs; air-sea chemistry and dissolved gases; whole-ecosystem experiments; particulate organic matter degradation and flux; and long-term research and databases. E-mail your abstract by 16 October 1997 to http://www.agu.org.

In addition to the many general sessions, there will be some special sessions. If you would like to propose a special session for this meeting, we encourage you to contact one of the program chairpersons (at the address below) as early as possible, but no later than 30 May 1997.

For additional information contact either one of the program chairpersons: Silvia L. Garzoli, NOAA/AOML, Physical Oceanography Division, 4301 Rickenbacher Causeway, Miami, FL 33143 (tel: 305-361-4338; fax: 305-361-4412; e-mail: garzoli@aoml.noaa.gov) or Linda Duguay, Office of Polar Programs, National Science Foundation, 4201 Wilson Blvd., Arlington, VA 22230 (tel: 703-306-1033; fax: 703-306-0139; e-mail: lduguay@nsf.gov). (5/97)

\section{Announcement}

The International Conference on Monsoon and Hydrologic Cycle, 21-23 April 1998, Kyongiu, Korea

The International Conference on Monsoon and Hydrologic Cycle, sponsored by the Korean Meteorological Society will be held 21-23 April 1998 in Kyongju, Korea. The American Meteorological Society is a cooperating organization.

It is well known that the Asian monsoon is the principal component not only in the regional circulation but also in the global circulation. More than $50 \%$ of annual rainfall in most regions of Asia occurs during summer monsoon months, June to September. Breaks in summer monsoon over the Asia region contribute to interannual variability of monsoon seasonal precipitation. Therefore, their prediction is very important for its great economic value.

The purpose of this conference is to bring together a group of scientists interested in the various aspects of monsoon circulations and socio-economically important regional consequences with the goal of encouraging research and international collaboration in this vitally important research area. The primary objectives of this conference are 1) to encourage the application of new findings to operational meteorology; 2) to provide the international forum for exchange of recent and innovative advances in these related fields of research; 3 ) to provide a forum for interaction between meteorologists and environmental scientists; and 4) to encourage regional cooperation in meteorological and environmental issues.

The conference will be conducted in English, and the program structure for the meeting will consist of both oral and orally introduced poster presentations, as well as keynote addresses from several noted authorities in the field of each session. For further information, contact Soon-Ung Park, The Korean Meteorological Society, c/o Dept. of Atmospheric Sciences, Seoul National Univ., San 56-1, Shinlim-Dong, Kwanak-Ku, Seoul, 151742, Korea (tel: 02-882-1541; fax: 02-882-1541). (4/97)

\section{Announcement}

\section{Ninth Conference on Satellite Meteorology and Oceanography, 25-29 May 1998, Paris, France}

The Ninth Conference on Satellite Meteorology and Oceanography, sponsored by the American Meteorological Society, the European Organization for the Exploitation of Meteorological Satellites (EUMETSAT), the Intergovernmental Oceanographic Commission of UNESCO, and the Societe Meteorologique de France, is planned for 25-29 May 1998 in Paris, France. The meeting venue is being finalized, and is scheduled to be held at the UNESCO facilities, with lodging to be arranged at surrounding hotels at the discretion of the local organizing committee. A joint program committee has been organized and a formal call for papers will be published in a future issue of the Bulletin. Special sessions relating to the "Year of the Ocean" are being planned. Given the breadth of remote sensing work conducted by members of the sponsoring organizations, it is anticipated that the Call for Papers will elicit a larger than normal response. Tailoring of the usual oral/poster presentation format may result in order to maximize this unique opportunity for dialogue among the international remote sensing communities. 
For more information contact the Program Chairperson: Marie Colton, Office of Naval Research, Code 321SR, 800 N. Quincy St., Arlington, VA 22217-5000 (tel: 703-696-1291; fax: 703-696-2007). (3/97)

\section{Call for Papers}

\section{Seventh International Meeting on Statistical Climatology, 25-29 May 1998, Whistler, BC, Canada}

The Seventh International Meeting on Statistical Climatology will take place 25-29 May 1998 at the Whistler Conference Centre in Whistler, BC, Canada. The American Meteorological Society is a cooperating organization. Several leading statisticians and climatologists will be presenting recent work on a variety of aspects of statistical climatology. The program consists of contributed, invited, and special invited sessions. The special invited sessions will cover issues in Bayesian methods, space-time filtering, wavelet analysis, Markov chain Monte Carlo methods, climate extremes, short-term climate forecasting, neural networks, climate model assessment, and low frequency variability. More information about the meeting is available on the World Wide Web at URL http://www.stat.washington.edu/peter/7IMSC/.

The deadline for contributed abstracts is 15 December 1997. The web site will have a form for abstract contribution as well as information about registration and hotel reservations. (4/97)

\section{Announcement}

International Symposium "Rossby-100," 812 June 1998, Stockholm, Sweden

The International Symposium "Rossby-100," sponsored by the International Meteorological Institute in Stockholm (IMI) and the Swedish Geophysical Society and organized by the Department of Meteorology, Stockholm University (MISU), will be held 8-12 June 1998 in Stockholm, Sweden. The symposium will be held to commemorate the 100th anniversary of the birth of Professor Carl-Gustaf Rossby. The American Meteorological Society is a cooperating organization.

The symposium will have three main themes: 1) geophysical fluid dynamics, 2) numerical modeling of weather and climate, and 3) global cycling of trace gases and aerosols. Plenary sessions, with invited speakers, are planned along with two parallel oral and poster sessions for contributed papers. There will be a special issue of Tellus, the journal of the Swedish Geophysical Society, for papers presented at the symposium. A preprint volume with submitted abstracts will be available at the symposium.

For further information, contact the local organizing committee at Dept. of Meteorology, Stockholm Uni- versity, S-106 91 Stockholm, Sweden (e-mail: sympos@misu.su.se) (4/97)

\section{Call for Papers}

\section{AMS Conference on Cloud Physics, 17-21 August 1998, Everett, Washington}

The AMS Conference on Cloud Physics, sponsored by the American Meteorological Society and organized by the AMS Committee on Cloud Physics, will be held 17-21 August 1998 at the Howard Johnson's PlazaHotel in Everett, Washington. Papers are encouraged on all aspects of cloud and precipitation physics and chemistry. The conference will be held in conjunction with the AMS 14th Conference on Planned and Inadvertent Weather Modification and is timed to partially overlap the Joint Conference of the Ninth Symposium of the International Association of Meteorology and Atmospheric Sciences (IAMAS) Commission of Atmospheric Chemistry and Global Pollution (CACGP) and the Fifth Symposium of the International Global Atmospheric Chemistry (IGAC) being held on the University of Washington Campus in Seattle from 19-25 August 1998. Cloud and precipitation chemistry sessions at the AMS cloud physics conference will be scheduled on 1718 August so that scientists interested in these disciplines can attend both the AMS cloud physics and IAMAS-CACGP-IGAC conferences.

Titles and abstracts (300 words maximum) including author(s) names(s), affiliation(s) and complete mailing address, telephone, fax number, and e-mail address of the corresponding author should be sent or e-mailed to the program chairman, Robert M. Rauber, Department of Atmospheric Sciences, University of Illinois, 105 S. Gregory Ave, Urbana, IL 61801 (tel: 217-333-2835; fax: 217-244-4393; e-mail: r-rauber@uiuc.edu) by 1 March 1998. Please state a preference for oral or poster presentation. Accepted papers must be presented by one of the authors and only one presentation per person will be allowed. Authors of accepted papers and invited presentations will be expected to contribute to a preprint volume. Completed camera-ready manuscripts (page length to be determined at a later date), including photos and diagrams, must be submitted to AMS Headquarters no later than 2 June 1998 A preprint volume will be distributed to participants at the conference. Page charges and additional charges for photo processing will be assessed to defray printing costs.

Updated information about the AMS Cloud Physics Conference can be obtained on the World Wide Web at http://www.atmos.uiuc.edu/cloud_phys_conf/ cloud_phys_conf.html. Information about the IAMASCACGP-IGAC conference can be obtained at http:// saga.pmel.noaa.gov/cacgp98/. (1/97; r2/97) 


\section{Call for Papers}

14th Conference on Planned and Inadvertent Weather Modification, 20-22 August 1998, Everett, Washington

The 14th Conference on Planned and Inadvertent Weather Modification, sponsored by the American Meteorological Society and organized by the AMS Committee on Planned and Inadvertent Weather Modification, will be held 20-22 August 1998, in conjunction with the AMS Conference on Cloud Physics.

Papers germane to those interested in cloud physics as well as weather modification will be presented at joint sessions during the final two days of the cloud physics conference (20 and 21 August 1998), while those dealing with topics more uniquely of interest to weather modification will be presented at a different time, independent of the cloud physics conference.

There has recently been a resurgence of interest in weather modification in the United States and abroad as dry conditions, coupled with a long-term dwindling of water resources, has turned attention back to weather modification as a possible partial solution. This has resulted in an increased need to scientifically validate and quantify the extent to which weather modification can offer relief to areas in need of additional water. In addition, significant advances are being made in the study of anthropogenic influences on atmospheric and cloud microphysical characteristics, and their possible feedbacks to climate-scale processes.

Specific topic areas for the conference include, but are not limited to, recent developments in understanding natural cloud processes and how they might be modified, development and refinement of conceptual models, application of numerical cloud models to weather modification topics, cloud seeding technology, physical evidence on the effects of weather modification programs, pollution effects on cloud microphysical parameters and processes, and societal and economic effects of human-induced weather and climate impacts. This conference will attempt to address these and other issues through a series of papers, posters, and panel discussions dealing with the scientific results of past and present research and operational programs. Authors wishing to contribute papers or post- ers on any aspect of planned or inadvertent weather modification should submit a brief abstract (via e-mail, if possible) of approximately 200 words by 5 January 1998. The abstracts should be submitted to the Program Chairperson, Tony Grainger, Box 9006 University Station, University of North Dakota, Grand Forks, ND 58202 (tel: 701-777-3170; fax: 701-777-5032; e-mail: grainger@aero.und.edu). Please provide complete mailing and e-mail addresses along with telephone and fax numbers. AMS will provide instructions to authors of accepted abstracts. Complete, camera-ready manuscripts (page length to be determined at a later date) including photos and diagrams, must be submitted no later than 1 May 1998 to AMS Headquarters. Page charges and any additional charges for photo processing will be assessed to defray printing costs. Registrants will receive a preprint volume at the conference. For further information, please contact the program chairperson at the above address or either of the program committee members: Bob Czys (tel: 217-333-8496) or Melanie Wetzel (tel: 702- 677-3137). (1/97; r3/97)

\section{Eighth Conference on Mountain Meteorology, 1998}

The Eighth Conference on Mountain Meteorology organized by the AMS Committee on Mountain Meteorology and sponsored by the American Meteorological Society will be held in 1998 . Due to the limited housing accommodations in Vancouver, this conference is being rescheduled and new deadlines and meeting information will be published in future issues of the Bulletin.

The Conference on Mountain Meteorology has established a tradition of providing an interdisciplinary forum on the effects of complex terrain on the atmosphere, over a wide-range of spatial and temporal scales. Theoretical, numerical, and observational papers are solicited in all areas of mountain meteorology, including the role of mountains in climate and the general circulation, mountain waves, downslope windstorms, mountain-valley circulations, effects of complex terrain on air quality, and topographically trapped disturbances.

The conference chairperson is Teddie Keller, NCAR, P.O. Box 3000, Boulder, CO 80303 (tel: 303-497-8428; fax: 303-497-8401; e-mail: tkeller@ncar.ucar.edu). (8/96; r11/96; r12/96) 